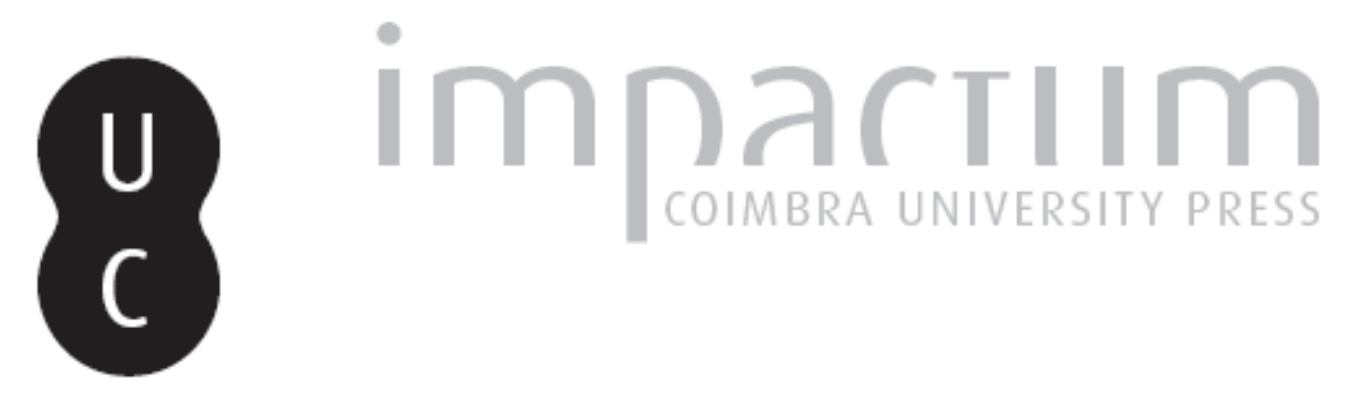

\title{
Uma cruzada verbal
}
Autor(es):
Azevedo, Maria Teresa Schiappa de
Publicado por:
Associação Portuguesa de Estudos Clássicos; Instituto de Estudos Clássicos
URL persistente:

DOI:

URI:http://hdl.handle.net/10316.2/30388

DOI:http://dx.doi.org/10.14195/0872-2110_52_8

Accessed : $\quad$ 26-Apr-2023 14:08:03

A navegação consulta e descarregamento dos títulos inseridos nas Bibliotecas Digitais UC Digitalis, UC Pombalina e UC Impactum, pressupõem a aceitação plena e sem reservas dos Termos e Condições de Uso destas Bibliotecas Digitais, disponíveis em https://digitalis.uc.pt/pt-pt/termos.

Conforme exposto nos referidos Termos e Condições de Uso, o descarregamento de títulos de acesso restrito requer uma licença válida de autorização devendo o utilizador aceder ao(s) documento(s) a partir de um endereço de IP da instituição detentora da supramencionada licença.

Ao utilizador é apenas permitido o descarregamento para uso pessoal, pelo que o emprego do(s) título(s) descarregado(s) para outro fim, designadamente comercial, carece de autorização do respetivo autor ou editor da obra.

Na medida em que todas as obras da UC Digitalis se encontram protegidas pelo Código do Direito de Autor e Direitos Conexos e demais legislação aplicável, toda a cópia, parcial ou total, deste documento, nos casos em que é legalmente admitida, deverá conter ou fazer-se acompanhar por este aviso.

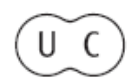




\section{Boletim de}

\section{Estudos Clássicos}

Associação Portuguesa de Estudos Clássicos Instituto de Estudos Clássicos

Coimbra

Dezembro de 2009 


\section{UMA CRUZADA VERBAL}

A aprendizagem de uma língua e a capacidade de uso, nela pressuposta, passam em grande parte pelo desfazer de barreiras psicológicas que, de forma mais ou menos inconsciente, tendem a relevar a "estranheza" de estruturas frásicas, morfológicas, vocabulares... - acentuada a todo o momento pelo inevitável confronto com a língua-mãe. No que toca ao Latim, essas barreiras são, como todos sabemos, ainda mais óbvias, pelo facto de ser uma disciplina de aprendizagem relativamente tardia e, sobretudo, pela falta de um enquadramento quotidiano, que só faria sentido num âmbito generalizado de língua de comunicação, agora confinado a sectores restritos da Igreja Católica.

No concertamento de estratégias utilizadas reside, assim, a possibilidade de êxito para uma interiorização eficaz das estruturas do Latim, onde a componente lúdica assume parte importante, mobilizando de forma mais imediata a criatividade do aluno e o seu sentido de colaboração na detecção de padrões estruturais ou de outras relações linguísticas, de que resultam benefícios sensíveis para o progresso da língua. A pedagogia moderna tem recorrido, dentro dos condicionalismos decorrentes de uma gestão eficaz dos tempos lectivos, a esta modalidade de abordagem, desde textos em Latim rediuiuus - de tonalidade quotidiana e humorística - aos textos mais breves de banda desenhada ou a actividades diversas (jogos, adivinhas, etc.), em que a capacidade e os conhecimentos do aluno são testados e estimulados segundo parâmetros e objectivos específicos. Inseremse neste último grupo os exercícios de palavras cruzadas, que alguns métodos incluem como complemento a matérias estudadas, e de que temos apresentado algumas propostas não sistemáticas.

O desafio a que procuramos responder aqui é a aplicação relativamente regular dos otia cruciata a etapas do estudo da flexão verbal onde, mesmo a nível de revisão, os alunos menos treinados tendem a fazer (e prolongar ...) confusões. Escolhemos duas etapas de revisão - o sistema do presente (infectum) e o sistema do perfeito (perfectum) - onde por vezes as falhas de domínio na identificação e flexão dos temas da conjugação latina se traduzem em equívocos que se repetem de aluno para aluno. A interiorização das suas 
diferenças, em particular nos verbos mais frequentes (embora um exercício destes não dispense uma ou outra escolha mais rara), é facilitada pela listagem de verbos que se encontra a seguir e que o aluno deverá consultar para a resolução das equivalências pedidas. A utilização repetida desses verbos, no próprio exercício ou em exercícios diversos, pode ser um suporte valioso para a sua memorização, que o professor deverá identicamente estimular nas aulas. Com vista a uma maior eficácia, apresentamos os verbos não pela ordem alfabética e sim por conjugações, critério quanto a nós mais apropriado às diferenças de flexão ocorrentes na conjugação latina (em particular, no presente) que pretendemos aqui focar.

\section{Sistema do presente (infectum)}

Uma distinção, que o aluno nem sempre interiorizou, diz respeito a aspectos específicos da $1^{\mathrm{a}}$ e $2^{\mathrm{a}}$ conjugações (temas em -a e -e longos), por oposição à $3^{\text {a }}$ (temas em consoante, -u e -i breve) e à $4^{\text {a }}$ (temas em -i longo). As confusões mais frequentes que daí resultam dizem respeito à $3^{\mathrm{a}}$ pes. pl. do presente do indicativo, à formação do futuro e ao presente do conjuntivo. Mas outras diferenças há também, como o uso, neste último grupo, da vogal de ligação (-e longo) no imperfeito do indicativo, particípio presente e gerúndio/ gerundivo. A nossa selecção entre a $1^{\mathrm{a}}$ e a $2^{\mathrm{a}}$ conjugações, por um lado, e a $3^{\mathrm{a}}$ e $4^{\mathrm{a}}$, por outro, passando pela focagem lateral dos conjuntivos (cf. arer e nectant). Assim:

$3^{\mathrm{a}}$ pes. pl. pres. ind.

$1^{\text {a }}$ e $2^{\text {a }}$ conj. -nt (ama-nt, iace-nt)

$3^{\mathrm{a}} \mathrm{e} 4^{\mathrm{a}}$ conj.-unt (inscrib-unt, iaci-unt)

futuro simples

-bo, -bis, etc. (ama-bo, iace-bo)

-am, es, etc(inscrib-am, iaci-am)

A fim de que os alunos possam melhor dar-se conta das referidas distinções, escolhemos dois verbos parecidos - e frequentemente confundidos em tradição - de grupos diferentes: o v. iaceo e o v. iacio, que figuram juntos na listagem apresentada no fim. A observação deste caso poderá suscitar outros, cuja ocorrência em textos é também motivo regular de erros, e. g. pendeo (intr.) "estar suspenso (pendurado)” e pendo (trans.) “pendurar”, "pesar"; dico, is, ere "dizer" e dico, as, are "proclamar" (embora nestes últimos casos os verbos tenham a mesma etimologia, o que não sucede no caso anterior).

Após a realização das palavras cruzadas, será útil que o docente apresente o quadro destas distinções - ou, preferivelmente, orientá-la - 
catalogando as formas verbais mais importantes (que deverão incluir as dos verbos uenio e inuenio), a que convirá depois juntar o imperfeito do indicativo e o presente do conjuntivo, bem como as formas nominais, se já tiverem sido dadas.

Outro aspecto importante a focar, pelos frequentes equívocos que suscita, é a análise de homónimos e parónimos do tipo uertere: a) com o penúltimo e longo, apenas pode ser futuro (= uerteris, também com e longo); b) com o penúltimo e breve pode ser:

infinitivo presente activo - "virar"

$2^{a}$ pes. imperat. passivo - "sê virado"

$2^{\mathrm{a}}$ sg. pres. indic. passivo - "és virado(a)" = uerteris

Esta última forma ( $2^{\mathrm{a}}$ pes. sg. do presente do indicativo passivo $=$ uerteris) tem uso quase inexistente, para evitar o equívoco com imperativo; o mesmo não acontece com o futuro que, como dissemos já, tinha vogal longa. É justamente o uso desta forma em -ere que encontramos no início das Catilinárias de Cícero: Quousque tandem Catilina, abutere [= abuteris] patientia nostra?

Tratando-se de um verbo depoente, como é aqui o caso, abutere terá em princípio apenas duas escolhas (imperativo ou futuro), cuja opção o contexto revela sem dificuldade.

\section{Sistema do perfeito (perfectum)}

Aqui, a grande dificuldade não está apenas na observação e no estudo "verbo a verbo": está, antes de mais, numa síntese eficiente dos tipos de perfeito e sua memorização, de forma a enquadrar os exemplos seleccionados numa estrutura racional. Não iremos aqui desenvolver essa síntese, mas tão só resumir alguns dados de que o aluno deve partir para o entendimento deste tema verbal:

- Os verbos em vogal longa (-a, $-\underline{e},-\underline{i})$ tendem a normalizar o perfeito em -ui, precedido ou não de vogal longa:, citare/ cita-ui, cubare/ cub-ui; delere/ dele-ui, habere/ hab-ui; audire/ audi-ui (audii), aperire/ aper-ui. Mas em todas as conjugações ocorrem outros tipos de perfeito. A mais "regular" é, nesse aspecto, a primeira, geralmente em -aui, onde são raros os tipos de perfeito como cubui e onde só há dois perfeitos de outro tipo (de redobro): dare/dedi e sto/steti. 
- Outros tipos de perfeito ocorrem nas outras conjugações, mas especialmente na $3^{\text {a }}$ (temas em -i breve e em consoante). A seriação dos verbos por conjugações, no final do problema, permitirá ver que é nesta que se encontra a maior variedade de tipos de perfeito: a) em -ui, como serui; b) sigmáticos, como rexi; 3) de redobro, como tetigi; 4) por alongamento da vogal radical, como egi, feci. Um pequeníssimo número de perfeitos não tem característica, como bibere/ bibi (com i breve). Em totondi, de tondeo, pretendeu-se fazer o contraste com tetigisti, de tango: este último tem a vogal de redobro esperada (como o perfeito grego), enquanto totondi ilustra um pequeno número de verbos de redobro onde esse vocalismo é determinado pela vogal do tema, neste caso, -o (cf. cucurri, de curro, didici, de disco, etc.).

- Especificamente no tocante à selecção dos perfeitos incluídos, afigura-se-nos pertinente lembrar ainda o uso que poderá fazer-se, pelo menos em dois casos, de formas de presente: o presente agor, bem como os conjuntivos niteat e tangat, que colmatam os tipos de conjuntivo ocorrentes no exercício anterior, destinam-se a estabelecer uma correlação com as respectivas formas de perfeito - agor/ egi, niteat/ nitui (só referido na enunciação) e tangat/ tetigimus. No primeiro e no último destes confrontos, a diferença entre o tema de presente e o de perfeito é bastante clara, o que ajuda a compreender a extensão do perfeito em -ui: permite salvaguardar uma homogeneidade temática que nos outros casos não se verifica.

Com o objectivo de evitar dispersões, restringimo-nos às formas de perfeito indicativo. As restantes formas do tema de perfectum poderão ser objecto de outro exercício. De notar ainda algumas outras possibilidades de explicação adicional que um ou outro aspecto poderão sugerir: para os alunos que aprendem também grego, a referência ao dativo arcaico dos temas em -o ajuda a reflectir nas semelhanças de flexão entre as duas línguas (muito óbvias nas duas primeiras declinações); referências comuns ao exercício anterior devem, por sua vez, ser lembradas, e. g. no referente a ut, cujos usos principais (com indicativo e com conjuntivo) repartimos pelos dois exercícios.

- Alguns itens remissivos para aspecto do latim, eventualmente mais complexos, não impedem a realização deste exercício numa etapa de iniciação. Por exemplo, os valores de ut aqui assinalados com indicativo e no exercício anterior com conjuntivo, mesmo não tendo ainda sido referidos, preparam terreno para uma síntese indispensável em fases posteriores; as palavras da $3^{\text {a }}$ declinação encontradas - especialmente a distinção entre temas 
em -i e em consoante - permitem sínteses rápidas, em princípio associáveis aos demonstrativos, e. g. hic senex; hoc os; ea auis; id uer.

Notas ao critério de elaboração e apresentação dos exercícios:

- O exercício deve ser preenchido com maiúsculas, sendo o $\underline{u}$ uniformemente representado por V e o $\underline{\mathrm{i}}$, por I. O $\underline{\mathrm{u}}$ ou o $\underline{\mathrm{i}}$ vogais cruzam, portanto, com $\underline{\mathrm{u}}$ ou $\underline{\mathrm{i}}$ consoantes.

- As palavras de uma mesma fila são separadas por ponto e vírgula.

- Indicamos valores diferentes de uma mesma palavra ou de um homónimo por uma barra oblíqua: por exemplo, uertere "virar"/ "sê virado", etc; ou ires "(que) fosses"/ "irias".

\section{A - Infectum cruciatum}

$\begin{array}{llllllllllll}1 & 2 & 3 & 4 & 5 & 6 & 7 & 8 & 9 & 10 & 11 & 12\end{array}$

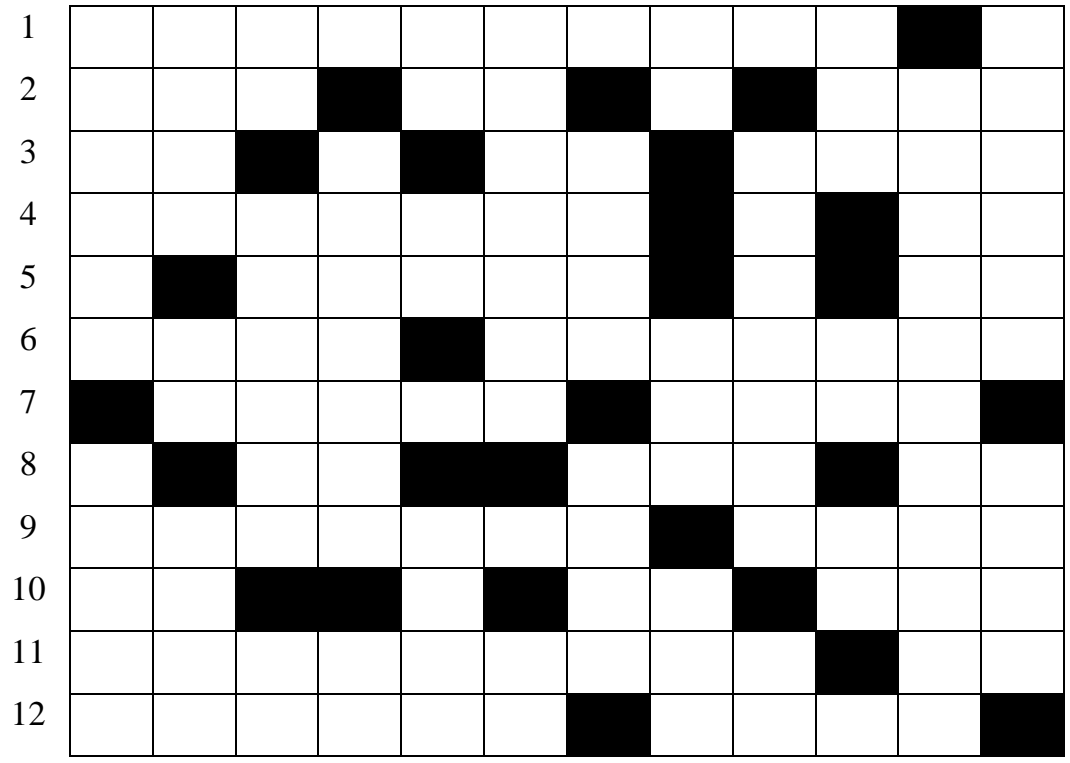


Horizontais:

1 - Gravam. 2 - À ave; ela/ esta; rua. 3 - 400 em romanos; partícula epidíctica posposta a alguns demonstrativos; esta (ac.). 4 - Hás-de jazer (jazerás); partícula posposta, equivalente a aut. 5 - Ânio (nome próprio); eis. 6 - Do (que está) são; (que eles) entrelacem. 7 - Ficou azedo; vi. 8 - Eis; ferida dos animais; prefixo grego com a ideia de "bem". 9 - Virar/ és virado, etc.; do som. 10 - Romanos; letra grega; letra grega. 11 - Mais antigo (abl.); terminação de nom. sg. masc. dos temas em -ọ.12 - A Ménio; (que eu) seja cultivado.

\section{Verticais:}

1 - Hás-de lançar (lançarás); das aves. 2 - Nua; vogal repetida; cidade de Itália, donde era originário Parménides. 3 - Se; chaga (cancro); te. 4 Vêm; eis. 5 - Prefixo que indica repetição; prefixo com ideia de 'dois'; do Euro. 6 - Lançam; donzela que Zeus seduziu e depois transformou em vaca, para escapar aos ciúmes de Hera. 7 - Ser; na verdade/ pelo contrário. 8 - 6 em romanos; por que razão? praia/ rostos. 9 - Hóstias (ac.); protagonista de uma viagem ao Além, no mito platónico da República. 10 - Tua; prefixo que designa aproximação; ditongo. 11 - Serão encontrados. 12 - Jazem; ruas (ac.).

\section{Verbos empregados neste exercício:}

sum, es, esse, fui - ser

aro, as, are, araui, aratum - cultivar

aceo, es, ere, acui , acetum - ficar azedo

uideo, es, ere, uidi, uisum - ver

iaceo, es, ere, iacui - jazer

iacio, is, ere, ieci, iectum - lançar

inscribo, is, ere, inscripsi, inscriptum - gravar

necto, is, ere, nexui, nexum - entrelaçar

uerto, is, ere, uerti, uersum - virar

uenio, is, ire, ueni, uentum - vir

inuenio, is, ire, inueni, inuentum - encontrar, descobrir 


\section{B - Perfectum cruciatum}

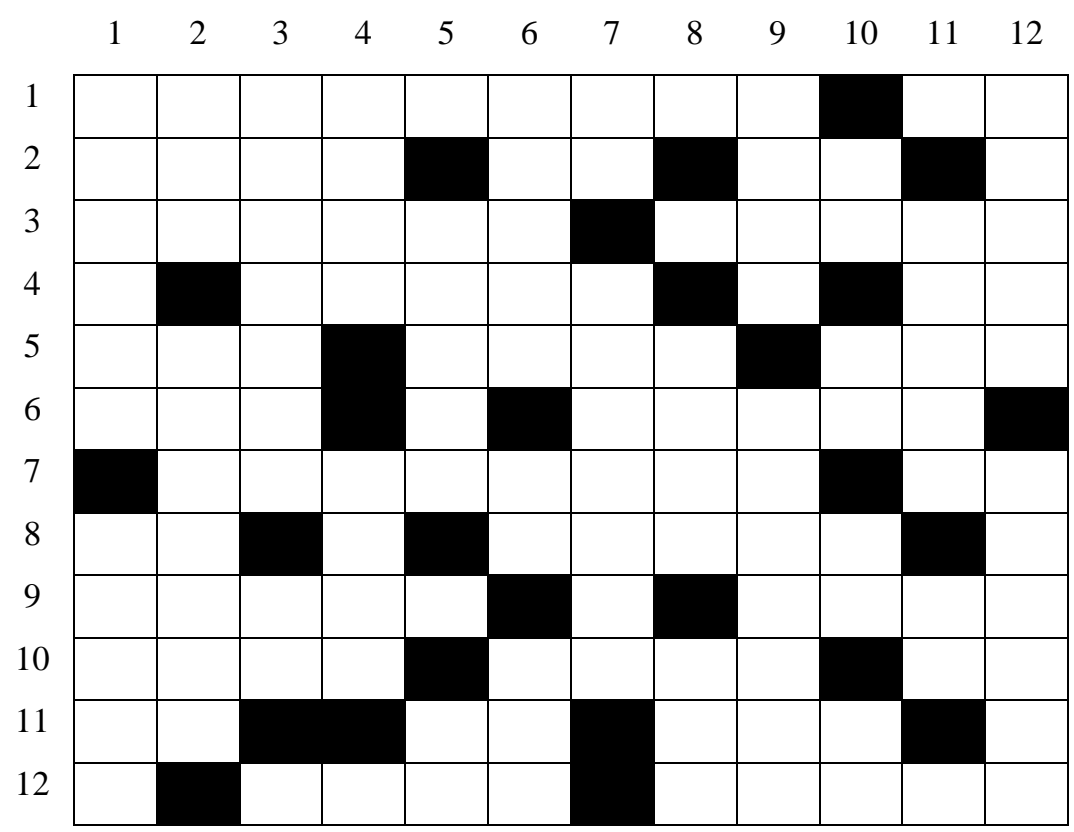

Horizontais:

1 - Tocámos; prep. de lugar donde. 2 - Sou impelido; forma contracta de nisi; ela/ esta. 3 - (Que ele) brilhe; antes. 4 - Dos ossos; conjunção integrante, final ou consecutiva, com conjuntivo.5 - = Aisne; deusa egípcia; serei. 6 - Forma arcaica de te; ao (que está) entrelaçado. 7 - Convocaram; ele/ este. 8 - Estes; puxei. 9 - Acção de queimar; a esse/ esses. 10 - (Que) vás repetidamente; vamos/ o que está mais dentro; prefixo grego que designa "bem”. 11 - 6 em romanos; prep. de lugar donde; letra grega. 12 - Fiz; riu/ sorriu.

\section{Verticais:}

1 - (Que ele) toque; deste. 2 - Impeli/ agi; lançaste. 3 - Cortei; te. 4 (Que) fosses/ irias; três vezes. 5 - Burra; = atque; 6 - Lá dentro; quando/ como com indicativo. 7 - Forma contracta de mihi; desgraçada (ac.)/ tinha enviado. 8 - Tarde; primavera. 9 - Velho (abl.); governaste. 10 - Por outro 
lado; e; ele/este; asse. 11 - Euro (dat. arcaico); te. 12 - Musa do amor; (ele) soube.

Verbos utilizados neste exercício:

cito, as, are, citaui, citatum - pôr em movimento, convocar

ito, as, are, itaui, itatum - ir frequentemente

niteo, es, ere, nitui - brilhar

rideo, es, ere, risi, risum - rir, sorrir

tondeo, es, ere, totondi, tonsum - cortar

sero, is, ere, serui, sertum - entrelaçar

ago, is, ere, egi, actum - impelir; agir, realizar

facio, is, ere, feci, factum - fazer, realizar

mitto, is, ere, misi, missum - enviar

rego, is, ere, rexi, rectum- governar, reinar

traho, is, ere, traxi, tractum - puxar, arrastar

tango, is, ere, tetigi, tactum - tocar

eo, is, ire, ii, itum - ir

scio, is, ire, sciui ou scii, scitum - saber

\section{Soluções}

\section{A - infectum cruciatum}

Horizontais:

1 - INSCRIBVNT. 2 - AVI; EA; VIA. 3 - CD; -CE; HANC. 4 IACEBIS; -VE. 5 - ANIVS; EN. 6 - SANI; NECTANT. 7 - ACVIT; VIDI. 8 - EN; VRA; EV. 9 - VERTERE; SONI. 10 - IL; RO; ETA. 11 VETERIORE; -VS. 12 - MAENIO; ARER.

Verticais:

1 - IACIES; AVIVM. 2 - NUDA; AA; ELEA. 3 - SI; CANCER; TE. 4 - VENIVNT; EN. 5 - RE; BI; EVRI. 6 - IACIUNT; IO. 7 - ESSE; VERO. 8 - VI; CVR; ORA. 9 - HOSTIAS; ER. 10 - TVA; AD; OE. 11 INVENIENTVR. 12 - IACENT; VIAS. 


\section{B - perfectum cruciatum}

Horizontais:

1 - TETIGIMVS; DE. 2 - AGOR; NI; EA. 3 - NITEAT; ANTEA. 4 OSSVM; VT. 5 - AIN; ISIS; ERO. 6 - TED; SERTO. 7 - CITAVERE; IS. 8 - HI; TRAXI. 9 - VSTIO; ISTI. 10 - ITES; IMUS; EV. 11 - VI; AB; ETA. 12 - FECI; RISIT.

Verticais:

1 - TANGAT; HVIVS. 2 - EGI; IECISTI. 3 - TOTONDI; TE. 4 IRES; TRIS. 5 - ASINA; AC. 6 - INTVS; VT; IBI. 7 - MI; MISERAM. 8 SERA; VER. 9 - SENE; REXISTI. 10 - AT; ET; IS; AS. 11 - EVROI; TE. 12 - ERATO; SCIVIT. 